\title{
Consumo voluntário e digestibilidade aparente da matéria seca, matéria orgânica, energia e parede celular das silagens de quatro genótipos de girassol (Helianthus annus)
}

[Voluntary intake and apparent digestibility of dry matter, organic matter, energy and cell wall components of silages of four sunflower (Helianthus annus) genotypes]

\author{
H.J.F. Ko ${ }^{1}$, R.B. Reis $^{2}{ }^{*}$, L.C. Gonçalves ${ }^{2}$, J.A.S. Rodrigues ${ }^{3}$, N.M. Rodriguez ${ }^{2}$, B.M. Sousa ${ }^{1}$ \\ ${ }^{1}$ Mestre em Zootecnia - EVUFMG \\ ${ }^{2}$ Departamento de Zootecnia da Escola de Veterinária da UFMG \\ Caixa Postal 567 \\ 30123-970 - Belo Horizonte, MG \\ ${ }^{3}$ Embrapa - Milho e Sorgo - Sete Lagoas, MG
}

\begin{abstract}
RESUMO
O valor nutricional de silagens de quatro genótipos de girassol (Rumbosol 91, M734, C11 e S430) foi avaliado a partir do consumo voluntário e da digestibilidade aparente da matéria seca, da matéria orgânica, da energia e dos componentes da parede celular. Vinte carneiros adultos foram alojados em gaiolas metabólicas, em delineamento inteiramente ao acaso, com quatro tratamentos e cinco repetições. Não foram observadas diferenças para consumo de matéria seca, matéria orgânica, energia digestível e metabolizável e dos componentes fibrosos entre os genótipos de girassol. A digestibilidade aparente da matéria orgânica foi superior para os genótipos R91, M734 e S430, no entanto não influenciou o consumo de matéria orgânica digestível. As silagens de girassol foram classificadas como alimento volumoso de boa qualidade, uma vez que o consumo de matéria seca foi acima dos requisitos recomendados para mantença animal, 63,6; 69,6; 50,2 e 74,5g MS/kg ${ }^{0,75} /$ dia para R91, M734, C11 e S430, respectivamente. O baixo coeficiente de digestibilidade aparente médio da FDN (32,3\%) e da FDA (28,7\%) foi conseqüência da baixa qualidade dos constituintes da parede celular das silagens de girassol utilizadas.
\end{abstract}

Palavras-chave: ovino, girassol, silagem, consumo, digestibilidade

\begin{abstract}
Voluntary intake and apparent digestibility of dry matter, organic matter, energy and cell wall components in silages of four sunflower genotypes (Rumbosol 91, M734, C11 and S430) were evaluated using 20 lambs in metabolic cages. A completely randomized design was used with four treatments and five replicates. No differences were observed among genotypes for dry matter, organic matter, digestible or metabolizable energy, neutral detergent fiber or acid detergent fiber intakes. Apparent digestibility of organic matter was higher for R91, M734 and S430 than for C11 genotypes, but not enough to influence digestible organic matter intake. All of the sunflower silages were classified as suitable roughages, because dry matter intake of each silage $\left(63.6,69.6,50.2\right.$ and $74.5 \mathrm{~g} \mathrm{DM} / \mathrm{kg}^{0.75}$ for R91, M734, C11 and S430, respectively) was higher than published maintenance requirement for the lambs. Low averages for apparent digestibility of NDF (32.3\%) and ADF (28.7\%) were due to the low quality of cell wall components.
\end{abstract}

Keywords: sheep, sunflower, silage, intake, digestibility

Recebido para publicação em 8 de maio de 2004

Recebido para publicação, após modificações, em 28 de abril de 2005

*Autor para correspondência (corresponding author)

E-mail: rbreis@vet.ufmg.br 


\section{INTRODUÇÃO}

Na maioria das regiões do Brasil, a produção bovina está sujeita às variações na disponibilidade e na qualidade de alimentos ao longo do ano. Por isso, a conservação de forragens torna-se alternativa viável para suplementação alimentar do rebanho no período de menor disponibilidade de alimentos (inverno), uma vez que a maior produção de matéria seca ocorre durante os meses de alta pluviosidade (verão). Dentre as práticas de conservação de forragens, destaca-se a ensilagem, que permite a utilização mais eficiente da terra e possibilita a produção de alimentos volumosos de elevado valor nutricional. A silagem de milho é considerada padrão, e seu valor nutritivo é tomado como referência, mas o alto valor comercial do milho grão, que é utilizado na alimentação humana e de animais não ruminantes, obriga a busca por novas alternativas. Em substituição ao milho como forrageira ensilada, cita-se o sorgo, mais tolerante à seca e com maior rendimento de massa verde (MV) por unidade de área (Almeida, 1992), e o girassol, ainda mais resistente que o sorgo ao estresse hídrico, por sua maior capacidade de retirar água do solo (Kakida et al., 1981). O cultivo do girassol na região Sudeste e Centro-Oeste do Brasil pode ser realizado após a retirada da cultura de verão, principalmente com semeadura a partir de fevereiro, ou em áreas onde sistemas já implantados permitem que espaços físicos, temporais e/ou agronômicos possam ser ocupados pelo girassol.

Vários autores citaram que o valor nutricional da silagem de girassol corresponde de 60 a $80 \%$ da silagem de milho (Vandersall e Lanari, 1973; Schingoethe et al., 1980). Almeida (1992), ao avaliar silagens de girassol, verificou consumos de proteína bruta e proteína digestível de 7,07 e $4,43 \mathrm{~g} / \mathrm{kg}^{0,75} / \mathrm{dia}$, respectivamente. Segundo Piccolo (1991), os consumos de matéria seca e de energia bruta da silagem de girassol foram $80 \mathrm{~g}$ e $298,6 \mathrm{Kcal} / \mathrm{kg}^{0,75} / \mathrm{dia}$, respectivamente. A digestibilidade aparente da silagem de girassol para proteína bruta $(\mathrm{PB})$, energia bruta $(\mathrm{EB})$, fibra em detergente neutro (FDN) e fibra em detergente ácido (FDA) foi, respectivamente, 63,9\% (Edwards et al., 1978), 67,6\% (Edwards et al., 1978), 51,6\% (Valdez et al., 1988 a) e 56,26\% (Almeida, 1992).
Este trabalho teve como objetivo determinar o valor nutritivo das silagens de quatro genótipos de girassol (Rumbosol 91, M734, C11 e S430), a partir do consumo voluntário e da digestibilidade aparente da matéria seca, matéria orgânica, energia e parede celular, em ovinos.

\section{MATERIAL E MÉTODOS}

Utilizaram-se silagens de quatro genótipos de girassol (Helianthus annus): Rumbosol 91 (R91), M734, C11 e S430. A colheita ocorreu quando as plantas encontraram-se na fase reprodutiva R9, caracterizada pela maturação fisiológica, com os aquênios maduros, as brácteas entre as cores amarela e castanho, folhas secas presentes na base da planta e o capítulo voltado para o solo com o dorso totalmente amarelado. Em um dia, as plantas foram cortadas, picadas e imediatamente ensiladas em 20 tambores metálicos com capacidade aproximada para 200 litros cada, revestidos internamente com sacos plásticos e vedados com o auxílio de travas nas tampas. A composição química das silagens utilizadas neste experimento é apresentada na Tab. 1.

Tabela 1. Composição química e energia bruta das silagens de girassol dos genótipos R91, M734, C11 e S430 com base na matéria seca

\begin{tabular}{|c|c|c|c|c|}
\hline $\begin{array}{l}\text { Componente } \\
\text { nutricional }^{1}\end{array}$ & R 91 & M 734 & C 11 & S 430 \\
\hline MS total, $\%$ & 22,27 & 23,03 & 25,10 & 22,50 \\
\hline $\mathrm{MO}, \%$ & 82,34 & 82,20 & 82,13 & 83,43 \\
\hline CZ, \% & 8,71 & 9,36 & 9,22 & 8,32 \\
\hline $\mathrm{PB}, \%$ & 8,75 & 10,42 & 10,11 & 9,03 \\
\hline $\mathrm{EE}, \%$ & 6,67 & 14,07 & 11,44 & 10,20 \\
\hline FDN, \% & 47,42 & 43,69 & 49,64 & 47,04 \\
\hline FDA, \% & 34,72 & 31,43 & 36,52 & 33,70 \\
\hline HCEL, \% & 12,71 & 12,26 & 13,12 & 13,35 \\
\hline CEL, \% & 27,50 & 24,57 & 29,21 & 27,32 \\
\hline LGN, \% & 7,21 & 6,85 & 7,31 & 6,37 \\
\hline $\mathrm{EB}, \mathrm{Kcal} / \mathrm{kg}$ & 4046,52 & 4396,94 & 4341,45 & 4301,48 \\
\hline $\mathrm{pH}$ & 3,79 & 4,07 & 4,56 & 3,84 \\
\hline $\mathrm{NH}_{3} / \mathrm{NT}, \%$ & 5,47 & 11,39 & 13,10 & 8,66 \\
\hline Ác. láctico, \% & 15,83 & 7,90 & 3,99 & 10,95 \\
\hline Ác. acético, \% & 2,41 & 1,95 & 4,25 & 2,65 \\
\hline \multicolumn{5}{|c|}{$\begin{array}{l}\text { MS: matéria seca; MO: matéria orgânica; CZ: cinzas; PB: } \\
\text { proteína bruta; EE: extrato etéreo; FDN: fibra em detergente } \\
\text { neutro; FDA: fibra em detergente ácido; HCEL: } \\
\text { hemicelulose; CEL: celulose; LGN: lignina; EB: energia } \\
\text { bruta; } \mathrm{NH}_{3} / \mathrm{NT} \text { : nitrogênio amoniacal em relação ao } \\
\text { nitrogênio total. }\end{array}$} \\
\hline
\end{tabular}


Para o ensaio de consumo voluntário e de digestibilidade aparente, foram utilizados 20 carneiros machos adultos, sem raça definida, pêlo curto, com peso corporal médio de $38,6 \mathrm{~kg}$, castrados e caudectomizados. Os animais foram alojados em gaiolas metabólicas individuais e adaptados às silagens de girassol experimentais por um período de 16 dias e às bolsas coletoras por seis dias. Após o período de adaptação, seguiu-se um período de quatro dias de amostragem, quando foi realizada pesagem e colheita individual de amostras do alimento fornecido e sobras no cocho, além de fezes e urina. As amostras de sobras no cocho, fezes e urina representavam alíquota de $10 \%$ do volume total obtido. Durante todo o experimento, os carneiros tiveram livre acesso à água e à mistura mineral.

Determinaram-se os teores de matéria seca (MS) em estufa a $105^{\circ} \mathrm{C}$, proteína bruta (PB) e conteúdo de nitrogênio $(\mathrm{N})$ pelo método de Kjedhal, extrato etéreo (EE) pelo método de Soxlet, energia bruta (EB) por combustão em bomba calorimétrica adiabática modelo PARR 2081 (Official... 1980), fibra em detergente neutro (FDN) e fibra em detergente ácido (FDA) pelo método seqüencial de Robertson e Van Soest (1981). As amostras de urina foram analisadas para os teores de energia bruta, por combustão em bomba calorimétrica adiabática modelo PARR 2081, enquanto a concentração de nitrogênio e de proteína bruta foi analisada pelo método de Kjedhal (Official... 1980).

Os valores de energia digestível (ED) foram obtidos pela diferença entre a EB dos alimentos ingeridos e das fezes. Os valores de energia metabolizável (EM) foram obtidos pela diferença entre energia digestível e perda de energia sob a forma de metano e urinária. Para cálculo das perdas em metano (CPM), considerando a situação de mantença, foi utilizada a fórmula sugerida por Blaxter e Clapperton (1965), CPM $=3,67+0,062 \mathrm{D}$, em que $\mathrm{D}$ representa $\mathrm{a}$ digestibilidade aparente da energia bruta do alimento.

A avaliação do consumo voluntário da MS das silagens foi determinada pela diferença entre a quantidade de material fornecido aos animais e as sobras nos cochos. Os valores de digestibilidade aparente dos nutrientes foram obtidos pela fórmula utilizada por Silva e Leão (1979) e Maynard et al. (1984).

O delineamento experimental foi o inteiramente ao acaso com quatro tratamentos, dos quais dois com quatro (R91 e M734) e dois com cinco (C11 e S430) repetições. Os dados obtidos foram submetidos às analises de variância utilizando-se o programa estatístico SAEG (Sistema... 1997) e as médias comparadas pelo teste Student Newman Keuls com probabilidade de 5\%. Uma repetição do genótipo R91 e outra do M734 foram retiradas da análise estatística devido à ausência de estabilização no consumo voluntário das silagens utilizadas.

\section{RESULTADOS E DISCUSSÃO}

Os valores de consumo voluntário e digestibilidade aparente da MS e da matéria orgânica (MO) são apresentados na Tab. 2. Não foram observadas diferenças $(\mathrm{P}>0,05)$ no consumo de matéria seca (CMS; $\mathrm{CV}=30,3 \%$ ) nas silagens dos diferentes genótipos (variação de 50,18 a 74,53g/ $\mathrm{kg}^{0,75} /$ dia). Os genótipos R91 e M734 apresentaram resultados intermediários. A digestibilidade aparente da matéria seca (DAMS; $\mathrm{CV}=8,6 \%)$ não foi diferente entre as silagens ( $\mathrm{P}>0,05$; variação de 46,9 a 53,6\%). $\mathrm{O}$ consumo de matéria seca digestível (CMSD; $\mathrm{CV}=35,1 \%$ ) também não foi diferente entre os genótipos (variação de 24,16 a 39,92g MSD/ $\mathrm{kg}^{0,75} / \mathrm{dia}$ ).

$\mathrm{O}$ consumo de matéria orgânica $(\mathrm{CMO} ; \mathrm{CV}=$ $30,3 \%$ ) seguiu o padrão do CMS, oscilando entre 42,37 e $63,08 \mathrm{~g} \mathrm{MO} / \mathrm{kg}^{0,75} / \mathrm{dia}$. A digestibilidade aparente da matéria orgânica (DAMO; $\mathrm{CV}=$ $6,0 \%)$ encontrada para a silagem do C11 (50,2\%) foi inferior às dos genótipos R91 e S430 (55,9\% e $54,5 \%$, respectivamente), enquanto a do M734 $(53,5 \%)$ resultou em valor intermediário. No entanto, o consumo de matéria digestível $(\mathrm{CMOD} ; \mathrm{CV}=33,2 \%)$ foi semelhante entre os quatro genótipos (variação de 21,53 a $34,35 \mathrm{gMO} / \mathrm{kg}^{0,75} /$ dia), mostrando que a diferença apresentada na DAMO não foi suficiente para influenciar o CMOD. 
Tabela 2. Consumo de matéria seca (CMS) e de matéria orgânica (CMO), g/ $/ \mathrm{kg}^{0,75} / \mathrm{dia}$, digestibilidade aparente da matéria seca (DAMS) e da matéria orgânica (DAMO), \%, consumo de matéria seca (CMSD) e de matéria orgânica digestíveis (CMOD), $\mathrm{g} / \mathrm{kg}^{0,75} / \mathrm{dia}$, das silagens, segundo os genótipos de girassol

\begin{tabular}{lccccc}
\hline Variável & $\mathrm{R} 91$ & $\mathrm{M} 734$ & $\mathrm{C} 11$ & $\mathrm{~S} 430$ & EPM \\
\hline $\mathrm{CMS}, \mathrm{g} / \mathrm{kg}^{0,75} / \mathrm{dia}$ & 63,60 & 69,59 & 50,18 & 74,53 & 19,44 \\
$\mathrm{CMO}, \mathrm{g} / \mathrm{kg}^{0,75} / \mathrm{dia}$ & 54,33 & 58,60 & 42,37 & 63,08 & 16,46 \\
$\mathrm{DAMS} \%$ & 53,60 & 53,29 & 46,91 & 53,44 & 4,46 \\
$\mathrm{DAMO}, \%$ & $55,94 \mathrm{a}$ & $53,49 \mathrm{ab}$ & $50,15 \mathrm{~b}$ & $54,50 \mathrm{a}$ & 3,18 \\
$\mathrm{CMSD}, \mathrm{g} / \mathrm{kg}^{0,75} / \mathrm{dia}$ & 34,37 & 37,43 & 24,16 & 39,92 & 11,84 \\
$\mathrm{CMOD}, \mathrm{g} / \mathrm{kg}^{0,75} / \mathrm{dia}$ & 30,53 & 31,58 & 21,53 & 34,35 & 9,74 \\
\hline
\end{tabular}

Médias com letras distintas na mesma linha diferem entre si pelo teste $\mathrm{SNK}(\mathrm{P}<0,05)$. EPM = erro-padrão da média.

O consumo voluntário de MS das silagens de girassol, sorgo e milho, em ovinos, segundo Almeida et al. (1995), foi $61,0 \mathrm{~g} / \mathrm{kg}^{0,75} / \mathrm{dia}$ para as silagens de girassol e de milho, e 56,7g/UTM/dia para as de sorgo. No entanto, o girassol foi ensilado com 90 dias pós-plantio, não caracterizando a fase em que a planta se encontrava em relação ao presente experimento. Rodrigues et al. (2001), ao utilizarem silagem de girassol produzida a partir do genótipo M734, colhido aos 99 dias de crescimento, para alimentação de ovinos, encontraram consumo de $2,5 \%$ do peso corporal, próximo ao encontrado neste experimento (valor médio de 2,6\%). Os resultados de consumo voluntário da $\mathrm{MS}$, expressos em porcentagem do peso corporal, citados por esses autores e os obtidos neste experimento sugerem boa aceitação da silagem de girassol pelos ovinos.

Leite (2002) trabalhou com vacas em lactação em regime confinado e dieta total (relação volumoso:concentrado de 56:44) e observou consumo de MS na dieta com $100 \%$ de silagem de girassol (M734) de 160,16g MS/ $/ \mathrm{kg}^{0,75} / \mathrm{dia}$ de dieta total ou $89,69 \mathrm{~g} \mathrm{MS} / \mathrm{kg}^{0,75} /$ dia somente de silagem. Os resultados desse autor, juntamente aos do presente experimento (média de 64,48g $\mathrm{MS} / \mathrm{kg}^{0,75} / \mathrm{dia}$ ), mostraram que o consumo de MS de silagem de girassol foi satisfatório e acima das exigências de mantença dos animais do experimento.

Perreira et al. (1993) mencionaram que os alimentos volumosos podem ser classificados como excelente, muito bom, bom, médio e ruim quando o consumo voluntário, expresso como porcentagem do peso corporal ( $\%$ do PC), foi 3,$5 ; 3,0 ; 2,5 ; 2,0$ e $1,5 \%$ do PC, respectivamente. As silagens testadas neste experimento foram classificadas como boas para os genótipos R91 (2,6\% do PC), M734 (2,7\% do PC) e S430 (3,0\% do PC) e média para o genótipo $\mathrm{C} 11$ (2,0\% do $\mathrm{PC})$.

Os valores do consumo voluntário de energia bruta, digestível e metabolizável, assim como o de digestibilidade aparente da energia bruta, são apresentados na Tab. 3. Não houve diferença $(\mathrm{P}>0,05)$ para os consumos $\left(\mathrm{Kcal} / \mathrm{kg}^{0,73} / \mathrm{dia}\right)$ de energia bruta $(\mathrm{CV}=29,9 \%)$, energia digestível $(\mathrm{CV}=32,4 \%)$, energia metabolizável ( $\mathrm{CV}=$ $33,8 \%)$ e para a digestibilidade aparente $(\%)$ da energia bruta $(\mathrm{CV}=4,7 \%$, isto é, variações de 228,65 a $331,04 \mathrm{Kcal} / \mathrm{kg}^{0,75} / \mathrm{dia} ; \quad 119,48$ a $182,01 \mathrm{Kcal} / \mathrm{kg}^{0,75} / \mathrm{dia} ; \quad 94,78 \quad$ a $148,00 \mathrm{Kcal} / \mathrm{kg}^{0,75} / \mathrm{dia} ;$ e 51,8 a $55,0 \%$, respectivamente.

Tabela 3. Consumo de energia bruta (CEB), de energia digestível (CED) e de energia metabolizável (CEM), Kcal $/ \mathrm{kg}^{0,75} /$ dia, digestibilidade aparente da energia bruta (DAEB), \%, e concentração de energia digestível (CEDG) e de energia metabolizável (CEMG), grama de matéria seca consumida (Kcal/g MS), das silagens, segundo os genótipos de girassol

\begin{tabular}{lccccc}
\hline Variável & $\mathrm{R} 91$ & $\mathrm{M} 734$ & $\mathrm{C} 11$ & $\mathrm{~S} 430$ & $\mathrm{EPM}$ \\
\hline $\mathrm{CEB}, \mathrm{Kcal} / \mathrm{kg}^{0,75} / \mathrm{dia}$ & 271,57 & 322,68 & 228,65 & 331,04 & 85,97 \\
$\mathrm{CED}, \mathrm{Kcal} / \mathrm{kg}^{0,75} / \mathrm{dia}$ & 147,96 & 178,22 & 119,48 & 182,01 & 50,63 \\
$\mathrm{CEM}, \mathrm{Kcal} / \mathrm{kg}^{0,75} / \mathrm{dia}$ & 118,68 & 144,63 & 94,78 & 148,00 & 42,54 \\
$\mathrm{DAEB}, \%$ & 54,30 & 54,88 & 51,76 & 54,98 & 2,51 \\
$\mathrm{CEDG}, \mathrm{Kcal} / \mathrm{g}$ & $2,32 \mathrm{~b}$ & $2,55 \mathrm{a}$ & $2,36 \mathrm{~b}$ & $2,44 \mathrm{ab}$ & 0,12 \\
$\mathrm{CEMG}, \mathrm{Kcal} / \mathrm{g}$ & $1,86 \mathrm{ab}$ & $2,06 \mathrm{a}$ & $1,87 \mathrm{~b}$ & $1,98 \mathrm{ab}$ & 0,13 \\
\hline
\end{tabular}

Médias com letras distintas na mesma linha diferem entre si pelo teste $\mathrm{SNK}(\mathrm{P}<0,05)$. EPM = erro-padrão da média. 
Apesar de não haver diferenças no consumo das variáveis de energia, a concentração (Kcal/g MS) de energia digestível $(\mathrm{CV}=5,0 \%) \mathrm{e}$ metabolizável $(\mathrm{CV}=6,7 \%)$ foi diferente entre os genótipos. A concentração de energia digestível $(C E D G)$ foi superior $(\mathrm{P}<0,05)$ para o genótipo M734 em relação aos genótipos R91 e C11, mas semelhante $(\mathrm{P}>0,05)$ quando comparado ao S430. Para concentração de energia metabolizável (CEMG), verificou-se superioridade $(\mathrm{P}<0,05)$ do genótipo M734 sobre o $\mathrm{C} 11$, sendo os valores intermediários $\mathrm{e}$ semelhantes entre si. A superioridade da silagem do M734 foi mais evidente em relação ao genótipo $\mathrm{C} 11$.

CEDG e CEMG foram influenciadas pelo CMS e pelo teor de extrato etéreo das silagens, pois o maior consumo de energia por grama de silagem consumida foi do genótipo M734, com maior teor de EE, que pode ter contribuído para o incremento energético do alimento consumido.

Almeida et al. (1995), ao avaliarem a utilização de silagens de girassol, milho e sorgo na alimentação de ovinos, relataram consumo de energia bruta superior para as silagens de girassol e milho $\left(298,6\right.$ e $297,9 \mathrm{Kcal} / \mathrm{kg}^{0,75} / \mathrm{dia}$, respectivamente) em relação à silagem de sorgo $\left(279,3 \mathrm{Kcal} / \mathrm{kg}^{0,75} / \mathrm{dia}\right)$. O mesmo padrão de consumo foi observado para a energia digestível: 198,9 e $199,7 \mathrm{Kcal} / \mathrm{kg}^{0,75} /$ dia para as silagens de girassol e de milho, respectivamente, e $178,3 \mathrm{Kcal} / \mathrm{kg}^{0,75} /$ dia para a de sorgo. O consumo de energia mostrou tendência semelhante à observada no consumo de matéria seca. A explicação baseou-se nas correlações encontradas por Almeida et al. (1995) entre essas duas características, cujos valores foram altos $\left(r_{\mathrm{CMS} \text { vs } \mathrm{CEB}}=0,9587\right.$ e $\left.\mathrm{r}_{\mathrm{CMS} \text { vs } \mathrm{CED}}=0,9393\right)$, o que justificaria a semelhança de comportamento.

A digestibilidade aparente e o consumo voluntário de FDN e de FDA são apresentados na Tab. 4. Os valores obtidos para o consumo de fibra em detergente neutro (CFDN; $\mathrm{CV}=29,2 \%$ ) e de fibra em detergente ácido (CFDA; $\mathrm{CV}=$ $29,5 \%$ ) variaram de 24,28 a $33,65 \mathrm{~g} / \mathrm{kg}^{0,75}$ e de 17,53 a $24,17 \mathrm{~g} / \mathrm{kg}^{0,75}$, respectivamente. Os valores da digestibilidade aparente da FDN (DAFDN; $C V=14,1 \%$ ) e da digestibilidade aparente da FDA (DAFDA; CV $=17,8 \%$ ) variaram entre 29,5 e $35,6 \%$ e 25,7 e $32,2 \%$, respectivamente. O CFDN digestível (CFDND; $\mathrm{CV}=35,1 \%$ ) e o CFDA digestível (CFDAD; $\mathrm{CV}$ $=35,7 \%$ ) variaram de 7,93 a $10,97 \mathrm{~g} / \mathrm{kg}^{0,75}$ e de 5,18 a $7,01 \mathrm{~g} / \mathrm{kg}^{0,75}$, respectivamente. Não houve efeito do genótipo da silagem de girassol sobre todas essas características estudadas $(\mathrm{P}>0,05)$.

Tabela 4. Consumo de fibra em detergente neutro (CFDN) e de fibra em detergente ácido (CFDA), $\mathrm{g} / \mathrm{kg}^{0,75} /$ dia, digestibilidade aparente da fibra em detergente neutro (DAFDN) e da fibra em detergente ácido (DAFDA), \%, e consumo de fibra em detergente neutro (CFDND) e de fibra em detergente ácido (CFDAD) digestíveis, $\mathrm{g} / \mathrm{kg}^{0,75} / \mathrm{dia}$, das silagens, segundo os genótipos girassol

\begin{tabular}{lccccc}
\hline Variável & $\mathrm{R} 91$ & $\mathrm{M} 734$ & $\mathrm{C} 11$ & $\mathrm{~S} 430$ & EPM \\
\hline CFDN, g/ $/ \mathrm{kg}^{0,75} / \mathrm{dia}$ & 29,54 & 30,06 & 24,28 & 33,65 & 8,55 \\
CFDA, g/ $\mathrm{kg}^{0,75} / \mathrm{dia}$ & 21,09 & 21,21 & 17,53 & 24,17 & 6,18 \\
DAFDN, \% & 35,62 & 29,48 & 31,52 & 32,41 & 4,54 \\
DAFDA, \% & 32,20 & 25,67 & 28,07 & 29,01 & 5,10 \\
CFDND, g/kg,75/dia & 10,52 & 9,09 & 7,93 & 10,97 & 3,37 \\
CFDAD, g/kg $/ 0,75 /$ dia & 6,73 & 5,60 & 5,18 & 7,01 & 2,19 \\
\hline
\end{tabular}

Médias na mesma linha não diferem entre si pelo teste $\mathrm{SNK}(\mathrm{P}<0,05)$. EPM = erro-padrão da média.

As maiores concentrações dos componentes da parede celular na composição química da silagem do genótipo C11 (Tab. 1) não influenciaram o CMS. Essa silagem apresentou as maiores concentrações de FDN $(49,6 \%)$ e de FDA $(36,5 \%)$, quando comparada com as silagens dos outros genótipos (R91, M734 e S430). O CFDN avaliado em relação ao peso corporal dos animais foi menor para a silagem do genótipo $\mathrm{C} 11$ (1,0\% do peso corporal) em relação aos das demais silagens $(1,2 \%, 1,4 \% \mathrm{e}$ $1,5 \%$ do peso corporal para M734, R91 e S430, respectivamente).

Rodrigues et al. (2001), ao avaliarem o valor nutritivo de silagens de girassol, encontraram digestibilidades aparentes da FDN e da FDA de 43,9 e $48,0 \%$, respectivamente. Henrique et al. 
(1998), ao estudarem a digestibilidade aparente da FDN e da FDA das silagens de girassol dos genótipos C11 e S530, encontraram 29,7 e 50,8\% e 32,5 e $52,0 \%$, respectivamente.

Valdez et al. (1988a) consideraram que a baixa digestibilidade da fração fibrosa foi devido às altas concentrações de EE (11,3\%). Segundo Elmeddah et al. (1991), a gordura na dieta de ruminantes tem diversos efeitos na degradabilidade da fibra. Também depende da natureza da dieta e do tipo de gordura presente (saturada, insaturada ou esterificada). Valdez et al. (1988b) relataram que a extração de gordura com solvente resultou em aumento na digestibilidade in vitro da matéria seca e da FDN em dietas completas baseadas em silagem de girassol.

Noguera (2000) estudou quatro genótipos de girassol (Rumbosol 91, DK180, M734 e V2000) ensilados com diferentes proporções de capítulo $(0,20,40,60,80,100 \%$ e planta inteira) e encontrou concentração média de FDN variando de 32,0 a $58,4 \%$, e de FDA de 30,1 a $51,6 \%$. O autor testou a digestibilidade ruminal da MS pela técnica in vitro do material original $\mathrm{e}$ desengordurado e encontrou variação de 61,6 a $48,7 \%$ para o material original, e de 61,4 a $48,1 \%$, para o material desengordurado, isto é, não houve efeito do extrato etéreo sobre a digestibilidade in vitro da MS. Para o autor, os valores de digestibilidades descrescem à medida que a quantidade de capítulo diminui, ou seja, menor proporção de material solúvel e maior concentração de parede celular no material ensilado.

Segundo Van Soest (1994), os componentes da parede celular são negativamente correlacionados com o consumo e a digestibilidade. Segundo Noguera (2000), foram observadas correlações negativas entre a digestibilidade in vitro da matéria seca (\% DIVMS) e as concentrações de FDN ( $\mathrm{r}=-0,68$; $\mathrm{P}<0,01)$ e FDA $(\mathrm{r}=-0,66 ; \mathrm{P}<0,01)$.

Com base nessas citações, o baixo valor de digestibilidade aparente (média) encontrado no presente experimento para a FDN $(32,3 \%)$ e para a FDA $(28,7 \%)$ pode ser explicado pela baixa qualidade da fração fibrosa das silagens de girassol, e não apenas por efeito depressivo do consumo de extrato etéreo sobre a digestão da fibra das silagens.

\section{CONCLUSÕES}

As silagens dos quatro genótipos de girassol podem ser classificadas como forrageiras de boa qualidade, com base na sua composição química e no seu valor nutritivo, expresso pelo consumo voluntário e pela digestibilidade aparente da MS, MO e energia. Os resultados indicaram boa aceitação da silagem pelos animais e sugeriram a possibilidade de utilização desses genótipos como alternativa na alimentação de ruminantes. Para os componentes fibrosos das silagens, o baixo coeficiente de digestibilidade aparente da fibra em detergente neutro e em detergente ácido pode ser explicado pela baixa qualidade da fração fibrosa das silagens de girassol.

\section{REFERÊNCIAS BIBLIOGRÁFICAS}

ALMEIDA, M.F. Composição química, digestibilidade e consumo voluntário das silagens de sorgo (Sorghum vulgare, Pers.) em dois momentos de corte, girassol (Helianthus annus, L.) e milho (Zea mays, L.) para ruminantes. 1992. 100f. Dissertação (Mestrado) Universidade Federal de Lavras, Lavras, MG.

ALMEIDA, M.F.; VON TIESENHAUSEN, I.M.E.V.; AQUINO, L.H. et al. Composição química e consumo voluntário das silagens de sorgo, em dois estádios de corte, girassol e milho para ruminantes. Ciênc. Prát., v.19, p.315-321. 1995.

BLAXTER, K.L.; CLAPPERTON, J.L. Prediction of the amount of methane produced by ruminants. Br. J. Nutr., v.19, p.511-522. 1965.

EDWARDS, R.A.; HARPER, F.; HENDERSON, A.R. et al. The potential of sunflower as a crop for ensilage. J. Sci. Food Agric., v.29, p.332 - 338, 1978.

ELMEDDAH, Y.; DOREAU, M.; MICHALETDOREAU, B. Interaction of lipid supply and carbohydrates in the diet of sheep with digestibility and ruminal digestion. J. Agric. Sci., v.116, p.437-445. 1991. 
HENRIQUE, W.; ANDRADE, J.B.; SAMPAIO, A.A.M. Silagem de milho, sorgo, girassol e suas consorciações. III. Coeficientes de digestibilidade. In: REUNIÃO ANUAL DA SOCIEDADE BRASILEIRA DE ZOOTECNIA, 35., 1998, Botucatu. Anais... São Paulo: SBZ, 1998.

KAKIDA, J.; GONÇALVES, N.P.; MARCIANI-BENDEZÚ, J. et al. Cultivares de girassol. Inf. Agropec., v.7, p.76 - 78, 1981.

LEITE, L.A. Silagem de girassol e de milho em dietas de vacas leiteiras em produção. 2002. 58f. Dissertação (Mestrado) - Escola de Veterinária, Universidade Federal de Minas Gerais, Belo Horizonte.

MAYNARD, L.A.; LOOSLI, B.S.; HINTZ, H.F. et al. Nutrição animal. 3.ed. Rio de Janeiro: Freitas Bastos, 1984. 726p.

NOGUERA, J.R.R. Qualidade das silagens de quarto cultivares de girasol (Helianthus annus) ensilados com diferentes proporções da planta. 2000. 34f. Dissertação (Mestrado) - Escola de Veterinária, Universidade Federal de Minas Gerais, Belo Horizonte.

OFFICIAL methods of analysis. 13.ed. Washington DC: AOAC, 1980. 1015p.

PEREIRA, O.G.; OBEID, J.A.; GOMIDE, J.A., et al. Produtividade de uma variedade de milho (Zea mays L.) e de três variedades de sorgo (Sorghum bicolor (L.) Moench) e o valor nutritivo de suas silagens. Rev. Soc. Bras. Zootec., v.22, p.31-38, 1993.

PICCOLO, M.A.; PAIVA, P.C.A.; TIESENHAUSEN, I.M.E.V. et al. Composição química e digestibilidade da silagem de sorgo (Sorghum bicolor (L.) Moench) sem partícula, enriquecida com aditivos e da silagem de sorgo integral. Ciênc. Prat., v.15, p.312-319, 1991)
ROBERTSON, J.B.; VAN SOEST, P.J. The detergent system of analysis an its application to human foods. In: JAMES, W.P.T.; THEANDER, $\mathrm{O}$. The analysis of dietary fiber in food. New York: Marcel Dekker, 1981. p.123-158.

RODRIGUES, P.H.M.; ANDRADE, S.J.T.; ALMEIDA, T.F. et al. Valor nutritivo de silagens inoculadas com bactérias ácido-lácticas. 3. Inoculação da silagem de girassol. In: REUNIÃO ANUAL DA SOCIEDADE BRASILEIRA DE ZOOTECNIA, 38., 2001, Piracicaba. Anais... São Paulo: SBZ, 2001.

SCHINGOETHE， D.J.; SKYBERG， E.W.; ROOK, J.A. Chemical composition of sunflower silage as influenced by additions of urea, dried whey and sodium hydroxide. J. Anim. Sci., v.50, p.625-629, 1980

SILVA, F.C.; LEÃO, M.I. Fundamentos da nutrição dos ruminantes. Piracicaba: Livroceres, 1979. 380p.

SISTEMA de análises estatísticas e genéticas SAEG. Versão 7.0. Viçosa: UFV, 1997.

VALDEZ, F.R.; HARRISON, J.H.; DEETZ, D.A. et al. In vivo digestibility of corn and sunflower intercropped as a silage crop. J. Dairy Sci., v.71, p.1860-1867, 1988a.

VALDEZ, F.R.; HARRISON, J.H.; FRASEN, S.C. Effect of feeding corn- sunflower silage on milk production, milk composition, and rumen fermentation of lactating dairy cows. J. Dairy Sci., v.71, p.2462 - 2469, 1988 b.

VAN SOEST, P.J. Nutritional ecology of the ruminants. 2.ed. Ithaca: Cornell University, 1994. 476p.

VANDERSALL, J.H.; LANARI, D. Sunflower versus corn silage at two grain ratios fed to cows. J. Dairy Sci., v.56, p.1384, 1973. (Abstract). 